\title{
Carl Einstein y el umbral heurístico de la pintura
}

\section{Carl Einstein and the heuristic threshold of Painting}

\author{
JOSÉ MARÍA DE LUELMO JAREÑO*
}

\begin{abstract}
Resumen: A lo largo de la Historia la relación entre filosofía y pintura ha trazado viajes de ida y vuelta que han venido fructificando en teorías y obras estrechamente ligadas entre sí. Especial interés presentan, en este sentido, las aportaciones del teórico alemán Carl Einstein, figura destacada de las primeras Vanguardias y autor de una originalísima lectura de la pintura sustanciada en un marcado antikantismo y en el empirocriticismo de Ernst Mach. Según Einstein, la dilución simultánea de sujeto y objeto en los procesos de creación y recepción de la obra pictórica es capaz de operar cambios de envergadura en el individuo y, en plena sintonía con el ideario vanguardista, en la propia configuración de la realidad.

Palabras clave: pintura, fuerzas, cubismo, metamorfosis, sujeto, recepción.
\end{abstract}

\begin{abstract}
Throughout history the relationship between philosophy and painting has drawn round trips that have borne fruit in theories and works closely intertwined. Particular interest have, in this sense, the contributions of the German theorist Carl Einstein, prominent member of the first Vanguard and author of a highly original reading of the painting marked by an acute antikantism and by the Empiriocriticism of Ernst Mach. According to Einstein, the simultaneous dilution of subject and object in the process of creation and reception of painting is capable of operating major changes in the individual and, in full harmony with the ideals of the Vanguard, in the very configuration of reality.

Key words: painting, forces, cubism, metamorphosis, subject, reception.
\end{abstract}

\section{Introducción: acerca de Carl Einstein}

Hay quien sostiene que revisar ciertos fenómenos arrumbados por la maquinaria moderna permite hallar alternativas o vías de escape a la Modernidad misma y, en buena ley, a las aporías que caracterizan nuestra circunstancia actual. En esta línea, Andreas Huyssen ha defendido la necesidad de sacar a flote ciertas partes sumergidas del iceberg moderno, especialmente «temas relacionados con el anarquismo semiótico de la vanguardia, con la figuración y la narrativa [...] con la tensión entre lo político y lo estético» ${ }^{1}$, y lo cierto es que, más por su carácter paradigmático que por mera coincidencia, el intelectual alemán Carl Einstein (1885-1940) reúne en su persona todos y cada uno de esos aspectos.

Fecha de recepción: 03/12/2012. Fecha de aceptación: 10/07/2013.

* Profesor Titular de la Universitat Politècnica de València. Doctor en Bellas Artes por la UPV y doctorando en Filosofía en la Universitat de València, donde elabora su tesis doctoral sobre la obra de Carl Einstein. Contacto: jolueja@pin.upv.es.

1 A. Huyssen: Modernismo después de la Posmodernidad, Barcelona, Gedisa, 2011, p. 12. 
Figura destacada del expresionismo - amigo de Gottfried Benn y asiduo colaborador de la mítica Die Aktion, donde en 1907 publicara su revolucionaria novela Bebuquin oder Die Dilettanten des Wunders ${ }^{2}$ - y más tarde del círculo Dada berlinés —en cuyo seno editara las revistas satíricas Die Pleite o Der blutige Ernst de la mano de George Grosz-, Einstein sostenía que ensanchar los márgenes de lo real requería que arte y teoría constituyesen en la práctica una sola actividad, crítica por definición ${ }^{3}$. Su nula afinidad con el estamento académico y su calificación de la estética como una «burocracia de las emociones» ${ }^{4}$ que estandariza el arte con vistas a su domesticación son, de hecho, lógica consecuencia de una militancia que se extendía desde las filas de la Vanguardia más feroz a las de la llamada extrema izquierda. Ajetreada observancia, por lo demás: habiendo participado en cenáculos de toda índole y en el movimiento espartaquista, tanto la represión subsiguiente como el amargo proceso judicial al que se viera sometido por injurias a la religión católica — supuestamente vertidas en 1921 en su drama satírico Die schlimme Botschaft - le forzarían a exiliarse en Francia y a hacer suya la máxima dictada por Maurice Blanchot, según la cual «el intelectual está tanto más cerca de la acción en general y del poder político cuanto menos se mezcle en la acción y menos poder político ejerza ${ }^{5}$. Inopinadamente, sin embargo, y tras década y media volcado en la escritura, un Einstein entrado en la cincuentena se incorporaría al Grupo Internacional de la Columna Durruti y permanecería junto a quienes perseguían una sociedad verdaderamente abierta hasta el mismísimo final de la contienda española. Apenas un año después, y a resultas de la ocupación alemana de Francia, a donde había regresado de nuevo, un Einstein carente de patria y de toda esperanza se quitaría la vida al pie de los Pirineos. Sin nadie que defendiera o difundiera su legado — razón suficiente para que fuese impunemente usurpado por supuestos amigos como Daniel-Henri Kahnweiler-, pocos recordarían su nombre hasta que alguien diera en rescatar sus escritos a mediados de los años sesenta, tarea que prosigue aún en la actualidad y a la que este artículo, en la medida de lo posible, quisiera venir a sumarse.

\section{Una cierta antiestética}

Precisamente como un passeur o Grenzgänger que atravesara fronteras en una y otra dirección para demostrar que el verdadero arte brota de un mismo y único impulso, desde bien pronto había entrado Einstein en contacto con los artistas franceses más avanzados al tiempo que promovía en París la obra de creadores alemanes aún desconocidos. Sin embargo, concernido por las interioridades del arte nuevo más que por su mera divulgación, ya en 1922 expresaba al propio Kahnweiler la intención de llevar a cabo un análisis exhaustivo

2 Hugo Ball, uno de los artífices del movimiento Dada, reconoce que en sus primeros años de actividad en Berlín «Los diletantes del milagro de Carl Einstein marcaban la dirección». H. Ball: La huida del tiempo, Barcelona, Acantilado, 2005, p. 39.

3 Sobre el lugar que ocupan los presupuestos einsteinianos en el panorama crítico de su tiempo, cfr. A. Strobl: «Die 'ringende Empfindung des Augenblicks'. Carl Einstein und die Kunskritik seiner Zeit», en K. Kiefer. (ed.): Die visuelle Wende der Moderne. Carl Einsteins Kunst des 20. Jahrhunderts, Múnich, Wilhelm Fink, 2003, pp. 99-109.

4 C. Einstein: «Exposition de collages (Galerie Goemans)», en AA.VV.: Documents. Doctrines, Archéologie, Beaux-arts, Ethnographie. Vol. I: 1929 (edición facsimilar), París, Jean-Michel Place, 1991, p. 244.

5 M. Blanchot: Los intelectuales en cuestión. Esbozo de una reflexión, Madrid, Tecnos, 2003, p. 56. 
de la obra del pintor Georges Braque ${ }^{6}$, análisis que vería finalmente la luz en 1934 al calor de una exposición monográfica comisariada por él mismo. En rigor, el pintor francés actúa en la obra como simple coartada para desplegar un plan que se quiere de largo aliento, a saber, nada más y nada menos que «la valoración moral y no solamente estética del arte»7. Hans Joachim Dethlefs sugiere que «Einstein experimenta la amoralidad como condición del empobrecimiento, como un mal difícilmente eludible» ${ }^{8}$ e inscrito en la generalizada pérdida de valores, luego, en esta tesitura, reconsiderar el arte desde una perspectiva moral debiera implicar su desvinculación con respecto del mercado y demás factores distorsionantes a fin de reintegrarle los originarios principios de causalidad y funcionalidad que en el curso de las décadas precedentes le habrían sido hurtados a manos del Privatkapitalismus. Sobra decir que semejante aspiración deriva del empeño vanguardista por antonomasia, este es, devolver el arte a la vida misma, pues «los vanguardistas — apunta Peter Bürger — buscaban una superación del arte en el sentido hegeliano del término, ya que el arte no había de ser destruido sin más, sino reconducido a la praxis vital, donde sería transformado y conservado», en el entendido de que «sólo un arte que se aparta de la praxis vital (deteriorada), incluso por el contenido de sus obras, puede ser el eje sobre el que se pueda organizar una nueva praxis vital». ${ }^{9}$

Como todo vanguardista que se precie, Einstein sostendrá que el arte convencional ha tocado a su fin porque no se emplea ni para comprender el mundo, ni para asimilarse a él, ni para desbordar sus márgenes sino, antes al contrario, para trasmutarlo en un sucedáneo manejable. «Sin duda en el arte clásico la realidad y el hombre fueron normalizados hasta un punto insoportable» ${ }^{10}$ en la creencia de que así se mantenía a raya toda creatividad verdadera y, por consiguiente, toda contingencia, luego una pintura que se pretendiera funcional y veraz habría de pasar ahora por encima de cualquier rigidez y constituirse en instrumento dotado de vida propia. En fórmula iluminadora donde las haya, Einstein resuelve que «si se exige del acto de crear y de los cuadros la fuerza necesaria para producir lo real, esto podrá resumirse mediante la frase: los cuadros no deben representar sino ser» ${ }^{11}$. No dispone que el cuadro, la pintura, el arte, deban transitivamente hacer esto o aquello, no les asigna una tarea y un modo de llevarla a efecto, sino que les exhorta a comportarse como aquello que, libres de toda servidumbre y de toda mordaza, ya son. Sometido a un uso meramente instrumental, acusa Einstein, «el arte ha sido demasiado a menudo considerado como una tentativa de ordenar la visión ya dada del mundo» cuando en esencia es exactamente lo opuesto, «un medio de rendir visible lo poético, de acrecentar la cantidad de formas y el desorden de lo concreto y, así, de reforzar lo absurdo e inexplicable de la existencia» ${ }^{12}$. Tras haber servido durante siglos a una didáctica del orden a medio camino entre lo psicológico

6 C. Einstein; D.-H. Kahnweiler: Correspondance 1921-1939 (Liliane Meffre ed.), Marsella, André Dimanche, 1993, p. 129.

7 Ibíd., p. 280.

8 H. J. Dethlefs: «Die Überwindung des Ästhetischen. Über Carl Einsteins Braque-Projekt», en AA.VV.: Text+Kritik (Múnich), nº5, 1987, p. 27.

9 P. Bürger: Teoría de la vanguardia, Barcelona, Península, 1987, pp. 103-4.

10 C. Einstein: Georges Braque, en Werke. Berliner Ausgabe, Band III. 1929-1940 (Hermann Haarmann, Klaus Siebenhaar eds.), Berlín, Fannei \& Walz, 1996, p. 360.

11 Ibíd., p. 325.

12 Ibíd., p. 376. 
y lo político, entre la narcosis y el atropello, los cuadros debieran renunciar de una vez para siempre a la tarea de representar porque «han degenerado en apariencias decorativas» ${ }^{13}$ que niegan la característica más genuina del arte, el hecho de ser una entidad viva en cuyo seno «la significación estética no tiene la menor importancia». ${ }^{14}$

A poco que repare uno en este enfoque se dará cuenta de su radicalismo, de su desvío con respecto a la relación convencional entre arte y realidad, aunque quizá para percibirlo mejor no haya nada como someterlo a fricción con el credo de Konrad Fiedler, por aquel entonces a la «vanguardia de la tradición». Así, mientras el gran teórico alemán basa lo que denomina principio de producción de realidad en el hecho de que «el arte no es sino uno de los medios mediante los cuales el ser humano conquista ante todo la realidad» ${ }^{15}$, es decir, en el poder del arte para dominarla y no, en sentido estricto, para crearla, Carl Einstein, por el contrario, considera que el arte funda lo real mediante su propia presencia, sin necesidad de trastocar o someter en modo alguno lo dado. Igualmente, al aforismo fiedleriano según el cual «la pintura muestra las cosas no como son sino como son vistas» ${ }^{16}$, Einstein replicará que lo pictórico no requiere modelo, referencia o preexistencia alguna, pues, en la medida en que rechaza la ilusión perspectiva y demás trucajes en favor de una neta materialidad, de un carácter puramente bidimensional, el cuadro es cósico en sí mismo, es real, es. «Los cuadros ya no tontean como metáforas de un real independiente y rígido sino que contienen una experiencia inmediata e inocente, luego ya no son ficticios sino realistas en razón de su inmediatez» ${ }^{17} \mathrm{o}$, lo que es lo mismo, su eficacia se establece en función de su capacidad para proponerse como un presente íntegro, como una factual y contundente Wirklichkeit (realidad). No ha de olvidarse, en este sentido, que es consustancial a la pintura moderna el hecho de potenciar su materialidad mediante una visibilidad máxima del soporte y de la sustancia pictórica, porque «si uno quería enérgicamente abandonar lo ilusionista —aduce Einstein- había que acabar con el cuadro como escenario de sustitución y, enfrentado a la fausse plastique, la superficie y la consumación de la planitud del cuadro devenían condiciones fundamentales» ${ }^{18}$. Lejos de convertirlo en masa inerte, este énfasis en la corporeidad del cuadro permitiría apreciar la dinámica de las formas, los ritmos y tensiones, las armonías y contrastes, todo aquello, en definitiva, que remite a la vida misma. Planteada la cuestión en estos términos, la relación entre arte y realidad nada tendrá ya que ver con grados de fidelidad o verosimilitud sino que poseerá los rasgos de una común identidad, pues siendo lo real «un complejo orgánico [...] un segmento modificado y desplazado sin cesar» ${ }^{19}$ y el arte su equivalente directo, será solamente «en tanto que centros de fuerzas en ebullición y cruces de experiencias que los cuadros poseen sentido». ${ }^{20}$

El freno a estas capacidades se encontraría, huelga decirlo, en la entrega del arte al juego mercantil y al simple juicio estético. Einstein, que jamás emplearía en sus escritos palabras

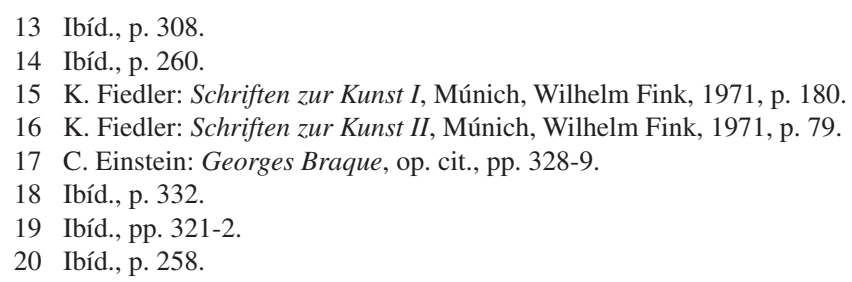


como gracia, proporción o belleza, conjetura en Die Fabrikation der Fiktionen (1932-1936) que «probablemente la perfección estética sólo se cumpla con material muerto» ${ }^{21}$, porque si la validez del arte reside en su grado de cercanía a un decálogo formalista, entonces bien puede afirmarse que o nace ya sin vida o es reducido a la nada a las primeras de cambio. Sucede así, arguye, porque temerosos de morir hay quienes proyectan su miedo sobre las obras de arte, «las desposeen de sus funciones vitales» ${ }^{22}$ y fuerzan a toda costa su perennidad, de modo que, paradójicamente o no, tales creaciones quedan mortalmente petrificadas en el instante mismo en que se promueve su inmortalidad o, de forma inversa pero idéntica, ganan la eternidad de las categorías estéticas al precio de una funesta vampirización. En estas circunstancias, «el arte, desvitalizado por el empleo de rancios clichés metafísicos e hipostasiado así en una trascendencia muerta, pierde su energía inductiva, de ahí que la actitud estética y el aislamiento de las obras de arte que conlleva entrañen una disminución y una limitación de esta energía ${ }^{23}$. Aunque ciertamente no escasean en Georges Braque, quizá existan pocos pasajes tan sobrecogedores como aquél donde se detallan las consecuencias que acarrea ese vaciamiento sustancial y funcional:

«Las obras de arte se me aparecen a menudo como espectros en acción. Quizá dormiten en las fosas de lo estático, pero acaparan las fuerzas de lo vivo y sus sombras deambulan entre nosotros. Completamente envueltas en la ilusión de la permanencia, acurrucadas al amparo de abrigos que recubren la falsa ausencia de toda finalidad, estas obras de arte me hacen pensar en amuletos y en fórmulas mágicas contra la muerte. Pero, como en su interior los acontecimientos han sido cazados por temor a ella, miran como difuntos que continuasen errando bajo la forma de espíritus. Se ha proyectado tanto en cuadros como en conceptos tal masa de crédula sobreestimación biológica que éstos actúan sobre el hombre mortal como impasibles fetiches venerados con devoción por razón de su inmortalidad. Para encontrar una justificación a esta creencia (el hombre) les ofrenda sus fuerzas y valores más fiables y espera que quizá contemplándolas un rayo de hierática inmortalidad caiga sobre él [...] Se crea así una zona de valores casi intocables que viene a reemplazar al antiguo cielo».24

Un más allá visible aquí mismo, entre nosotros, bajo la forma de un cortejo de «sombras» y «espectros» que, a la manera de la célebre mesa marxiana, danzan ensimismados. Ni que decir tiene que sólo cerrando el paso a toda veneración cultual, a todo canon coercitivo y a toda malversación de sus cualidades podrá zafarse el arte de tamaña tanatología, que únicamente si se propone como la antítesis del estatismo, del cálculo y de la consumación dejará de ser una demediada y pálida entidad y actuará de nuevo como «una fuerza viva y una herramienta práctica $»^{25}$ capaz de transformar la existencia toda.

21 C. Einstein: Die Fabrikation der Fiktionen (Sybille Penkert ed.), Reimbeck, Rowohlt, 1973, p. 258.

22 C. Einstein: Georges Braque, op. cit., p. 283.

23 Ibíd., p. 258.

24 Ibíd., pp. 305-6.

25 Ibíd., p. 255. 


\section{La buena pintura}

Según Einstein, la praxis donde más claramente cuaja esta manumisión es la instaurada por el cubismo, y es por ello por lo que viene a constituirse en exemplum de su peculiar dialéctica. Vanguardia anterior a la eclosión de las vanguardias, movimiento al margen del sectarismo, las fricciones internas o la pose combativa, aunque en principio pudiera parecer que el cubismo se compadece mal con las aspiraciones einsteinianas, lo cierto es que, tras décadas pulsando en carne viva el arte moderno y consagrando sus esfuerzos a analizarlo y fomentarlo en todos sus extremos, un Einstein en plena catarsis abominará de «esta retaguardia de artistas pompiers explotadores de nuevos hallazgos que vulgarizan demasiado rápidamente las visiones de los descubridores y las integran miedosa pero humillantemente en la reserva habitual del arte» ${ }^{26}$, y concluirá que sólo a los cubistas corresponde el papel de vanguardistas en sentido estricto, dado que devuelven al sujeto su capacidad gestora de lo real mediante una nueva forma de mirar y de asentar esa mirada. En manos cubistas, en efecto, la cuestión no pasa ya por proponer nuevas formas de recrear la realidad sino por dar con medios gráficos capaces de crear lo real, operándose así una reacción contra las circunstancias ambientales pero también contra la actividad de sus antecesores impresionistas, «que ciertamente habían disuelto y disminuido la estructura del motivo, pero que permanecieron encerrados en las tareas técnicas y no abordaron una modificación ni de las relaciones entre cosas ni del acto de ver» ${ }^{27}$.

Perfilándose así contra el fondo de los precedentes artísticos y de su entorno inmediato, sin deuda contraída ni ambiente propicio —es bien sabido que su nombre nace como un apelativo despectivo- - y aun siendo un movimiento exiguo y sobrio como pocos, el cubismo emprendería una operación de inusitada envergadura. En plena crisis del cambio de siglo la cuestión se plantearía en términos concluyentes: «si el espacio es algo estable e imposible de modificar, entones no queda precisamente más que una salida, la observación miserable y el ordenamiento halagador», lo cual «implica que la pintura se degrada al terreno del deporte», pero si por el contrario «la realidad es un conjunto que, orgánicamente, nace y muere al mismo tiempo ${ }^{28}$, es decir, si presenta las cualidades que Einstein asocia idealmente a la pintura, en tal caso ésta ha de zafarse para siempre de su carga atávica y replantearse por completo sus objetivos, sus métodos e inclusos sus materiales de trabajo, y exactamente eso es lo que hará el cubismo. «Con la revuelta de los cubistas el acto de pintar fue intensificado, más allá de toda dimensión técnica, en una violenta tentativa para reencontrar la libertad del cuadro» ${ }^{29}$, de suerte que «el artista franquea por fin la especialización de tipo artesanal» $»^{30}$ a la que le había relegado la liberale Bourgeoisie y se da a la ventura de establecer una reconfiguración del espacio pictórico que en último término promueva, por simpatía o por capilaridad, la del espacio vivencial en sí.

Hasta ese momento el espacio representado era un lugar de culto, una estancia bajo llave a la que sólo se accedía mediante el santo y seña de la norma perspectiva, luego ahora «se

26 Ibíd., p. 257.

27 Ibíd., p. 361.

28 Ibíd., p. 321 (todas las citas).

29 Ibíd., p. 327.

30 Ibíd., p. 316. 
trataba de dar finalmente el salto, de ya no maravillarse ante el acto de ver y del espacio como sólidas daciones, de no evaluarlo como un presupuesto sino de percibirlo como un problema y una tarea por cumplir» ${ }^{31}$. Ni preexistencia, ni contrato, ni entidad normalizada sino espacio abierto en el más amplio sentido de la expresión; «el espacio no constituía ya una condición regulada, sino el núcleo central de la invención» ${ }^{32}$, sentencia Einstein. Ahora bien, en aplicación del manual del buen vanguardista y del mismísimo programa einsteiniano, esa labor inventiva irá de la mano, necesariamente, de una acción destructiva, porque si el modelo en vigor no sirve a los efectos de un desarrollo de las capacidades humanas va de suyo que se acabe con él de manera expeditiva. «La imagen liberal de la realidad debía ser destruida; los propios liberales habían preparado este trabajo porque para ellos lo real había degenerado en fenómeno o en ficción $\gg^{33}$, y siendo así los cubistas acometieron el metódico desmantelamiento de un modo representativo de corte teatral — la simulación perspectivaque situaba al individuo frente a la paradoja de hallarse a la vez en el centro de la realidad y fuera de ella. La alternativa a ese artefacto estaba aún, literalmente, por ver, pues como indica Benjamin «al carácter destructivo no le ronda ninguna imagen. Tiene pocas necesidades y la mínima sería saber qué es lo que va a ocupar el lugar de lo destruido. De momento, por lo menos por un instante, el espacio vacío» ${ }^{34}$. Sostener, en cualquier caso, que el cubismo posee un sesgo violento porque en sus cuadros «se combatía la realidad existente» ${ }^{35}$ y en último término se infligía un daño irreparable — a todas luces necesario — a la tradición occidental, es argumentar sólo a medias si tomamos en cuenta que sus víctimas propiciatorias fueron ante todo las caducas nociones de sujeto y objeto implicadas en ella, es decir, si atendemos al hecho de que, a cuenta de la pintura, estaba en juego una reestructuración ontológica de fondo. Ahí se situará, justamente, el punto de máximo interés de Carl Einstein hacia el cubismo y hacia la pintura como tal, el núcleo duro de su teoría del arte.

\section{Taller de mundo}

«El pintor no trata de reconstruir una anécdota, sino de instaurar un hecho pictórico» ${ }^{36}$, afirma Georges Braque en 1917. Afirmación que, como tantas veces sucede con los escritos de artista, viene a desdecir mediante la experiencia personal creencias gestadas al calor de la ignorancia, pues si existe un prejuicio recurrente en quienes desconocen la calidad del acto pictórico es aquel que le atribuye una estricta programación y un preciso cálculo de incidencias. Según esta creencia, precisa Wollheim, «se contempla la intención como una especie de orden interno dirigido a uno mismo, por lo que se manda pintar de tal modo que el espectador identifique lo que se ha hecho según un patrón determinado» ${ }^{37}$, de tal forma que el proceso quedaría establecido de antemano en todos sus extremos y el pintor se limitaría a

31 Ibíd.

32 Ibíd., p. 313.

33 Ibíd., p. 273.

34 W. Benjamin: «Der destruktive Charakter», en Gesammelte Schriften, Band IV-I, (Tillman Rexroth ed.), Fráncfort del Meno, Suhrkamp, 1991, p. 398.

35 C. Einstein: Georges Braque, op. cit., p. 275.

36 G. Braque: El día y la noche, Barcelona, Acantilado, 2001, p. 17.

37 R. Wollheim: La pintura como arte, Madrid, Visor, 1997, p. 26. 
seguir obedientemente una secuencia de tareas conducentes a dicha identificación, partiendo para ello de una imagen proyectiva vinculada a una matriz perceptiva o mental y llegando a una imagen quirográfica subsidiaria, a un correlato físico de aquélla.

Justo es decir que esta interpretación se funda en un modo estructural —Einstein lo denominará clásico - regido las más de las veces por un propósito en torno al cual se articula la actividad pictórica, ese propósito o predeterminación que Braque tacha de anécdota puesto que desbarata el potencial de dicha práctica mediante su reducción a un mecanicismo ciego y ajeno a cualquier experimentación. Llegada la Modernidad, sin embargo, el artista «ya no podía reproducir las cosas sino que debía crearlas» ${ }^{38}$ en el curso del hecho pictórico, sirviéndose a tal efecto de una visión productiva, instantánea y genuinamente creadora, y no de reproducción o de previsión alguna. Aunque pueda parecer un ejercicio retórico afirmar que la mirada origina el mundo, que «la visión es la primera fase de lo real» ${ }^{39}$, conviene aclarar cuanto antes que en el programa einsteiniano ésta presenta un marcado carácter fisiológico, cumplidamente real, en abierta afinidad con las tesis empirocriticistas de Ernst Mach — «desde una perspectiva teórica, de quien estoy más cerca» ${ }^{40}$ — y en no menos abierta pugna con el neokantismo reinante en la época. A considerable distancia de su funcionamiento dentro del dogma kantiano - no en vano, en su inconcluso Traité de la vision, Einstein se referirá a ésta «como fijación de funciones dialéctica (antikantiana)» ${ }^{41}$, la mirada moderna estaría dotada de los máximos atributos de espontaneidad, movilidad y creatividad, y respondiendo como responde a «aquello que no ha sido aún entumecido y adaptado por las convenciones» ${ }^{42}$ se hallaría capacitada para desplegar una autonomía performativa que, contemplada desde las cumbres de la razón instrumental, evoca aquella fase inicial de la civilización o infantil de la existencia en la que el entendimiento actúa sine ira et studio y nada es por principio ni más conveniente ni más digno de estima que nada.

Aunque ésta es justamente la actitud que descubre en el cubismo y persigue extender a la vida común, Einstein se ve obligado a reconocer que ello entraña «una total entrega a lo desconocido ${ }^{43}$ tanto en lo referente a la exterioridad como en lo tocante al individuo en sí, ya que en las condiciones instituidas por la buena visión ni uno ni otro constituyen entidades fundadas de una vez por todas sino, antes al contrario, haces de fenómenos que se modifican sin solución de continuidad. La visión crea de facto el mundo pero también al individuo, es ella quien viene a fundarlo y no al revés, y sabedor de que en este aspecto descansa el fundamento de la práctica cubista y la clave para desmantelar la malsana ficción llamada subjetividad, Einstein no puede ser más concluyente cuando proclama que es inadmisible hablar de integridad alguna y que «la leyenda de la persona continua es ante todo el resultado de un miedo a la muerte» ${ }^{44}$. La sistemática fabricación de conceptos respondería a una actividad racional fundada en un pánico puramente animal, en un ataque preventivo — complejo y multiforme - contra la amenazadora selva de lo real, y en este esquema el

38 C. Einstein: Georges Braque, op. cit., p. 313.

39 Ibíd., p. 404.

40 C. Einstein; D.-H. Kahnweiler: Correspondance 1921-1939, op. cit., p. 144.

41 C. Einstein: Werke. Berliner Ausgabe, Band IV. Aus dem Nachlaß I, op. cit., p. 249.

42 C. Einstein: Georges Braque, op. cit., p. 314.

43 Ibíd., p. 394.

44 Ibíd., p. 314. 
yo constituiría una construcción más, «un estado de defensa cuya función principal reside en el establecimiento de una distancia protectora», toda vez que «las tendencias del yo y de la consciencia son ante todo agentes de protección que crean inhibiciones y evitan que la persona sea entera e incesantemente anulada dentro de la acción» ${ }^{45}$. Siendo como es un patrón elaborado en el seno de la civilización occidental, esta salvaguarda frente a la intemperie del mundo viviría su momento más feliz en el seno de la muy temerosa y muy soberbia intelectualidad moderna y encontraría en el liberalismo una ideología a su medida, de manera que Einstein no deja pasar la ocasión de denunciar que «aquello que se conoce como libertad subjetiva significa simplemente una disminución de lo real preciso» ${ }^{46} \mathrm{o}$, por mejor decir, una afirmación del yo individual a costa de la unidad objetiva.

Dadas las circunstancias, instituida una severa jerarquización sujeto-objeto donde nadie gana sino que todos pierden, si el individuo moderno quiere evitar la asfixia debe abrirse a la contingencia y propiciar un careo con el mundo en el que la pintura desempeñe un cometido esencial. «Actualmente el yo consciente está en trance de morir porque expresa ante todo una diferencia entre persona y objeto» ${ }^{47}$, y es en el cubismo y no en la filosofía o en la psicología donde halla Einstein una epistemología que no sólo devuelve el sujeto a la vida en el instante mismo de su ocaso — dado que «el yo [...] desaparece en el acto» ${ }^{48}$ — sino que lo engasta de nuevo en el mundo. Ahora bien, ¿cómo ejecuta la pintura esta operación, se preguntará uno, de qué modo puede saltar, con los precarios medios a su alcance, por encima del secular dualismo que marca a fuego la cultura occidental en todas sus manifestaciones? De entrada, ya se vio más arriba, desestimando para siempre la mímesis reproductora, en su calidad de preclara manifestación de esa separación de poderes, y consagrándose a un proceso netamente productor. «La doctrina de la imitación contiene secretamente la de un mundo autónomo y exterior, posición que había originado las formulaciones de forma y contenido, de mundo interior y exterior ${ }^{49}$, provechosas para la razón en el plano ejecutivo pero calamitosas en el ontológico, por cuanto instala a los intervinientes en posiciones fijas e irreconciliables. Como demostraba aquel género fuertemente connotado que es el paisaje y más si cabe su correlato doméstico, la bien llamada naturaleza muerta, bajo la mirada del pintor clásico los referentes «no son sino cristalizaciones de prejuicios» $»^{50}$, «sedimentos muertos y fijos de experiencias visuales» ${ }^{51}$, luego no es casual que el cubismo cuestione a fondo ambos géneros, sometiéndolos a revisión y empleándolos como coartada para aplicar principios completamente opuestos a los del sistema de pensamiento que los pusiera en pie. La introducción en los bodegones iniciales de Picasso y Braque de fragmentos auténticos

45 Ibíd., pp. 291-2. Si en referencia a su teoría de la visión reconoce Einstein la deuda contraída con Ernst Mach, qué decir de su concepción del sujeto. Cuando Mach afirma que «el yo no es una unidad inmutable, determinada, precisamente delimitada» y que seguir considerándolo como tal «es insostenible», siendo concebible si acaso «un yo como una unidad práctica para una observación provisional orientadora», es evidente que un Einstein a la busca de argumentos científicos para su modelo anticientífico está tomando buena nota. E. Mach: Análisis de las sensaciones, Barcelona, Altafulla, 1987, pp. 21, 22 y 26 resp.

46 Ibíd., p. 273.

47 Ibíd., pp. 380-1.

48 Ibíd., p. 405.

49 Ibíd., p. 359.

50 Ibíd., p. 370.

51 Ibíd., p. 389. 
—etiquetas, periódicos, embalajes, tramas de enea- abole de un solo golpe la distancia entre imagen y referente y crea una entidad conjunta que no es una segunda realidad sino «una realidad propia y especialmente precisa» ${ }^{52}$, tangible incluso, si bien mayor consistencia epistémica, en la medida en que sustituye el desgarro físico del objeto por una especie de empirismo delicado (la zarte Empirie goethiana), ofrecerá el registro puramente quirográfico del llamado cubismo analítico. Delicadeza engañosa la suya, pues no deja de ser un acto de fuerza: aunque en ambas variantes se da un asesinato de lo pseudorreal, un crimen contra la convención gastada, la devastación es notablemente mayor en el segundo caso porque aquí no queda rastro ni del objeto ni del sujeto que a cuenta del arte formulario creíamos conocer.

Con arreglo al paradigma racional, «el sujeto y el objeto representan, dentro de la experiencia inmediata, estados límites, extremos de la acción, y en el pensamiento, conceptos liminares y resistencias» ${ }^{53}$, como corresponde a un logos que dejó atrás la mitología, el animismo, las relaciones de semejanza y demás formas de sinergia. En este esquema óntico, precisa Einstein, el yo se hace rodear de una comunidad de objetos cuya indolencia, lejos de ser connatural, «corresponde a fases de pérdida de la vitalidad, a verdaderas inhibiciones funcionales $»^{54}$, a «condensaciones de actos mecanizados, rutinarios y laxos $»^{55}$. Mientras que antaño eran depositarios de fuerzas tanto específicas como genéricas que los caracterizaban individualmente y a la vez los situaban en plano de igualdad con el universo entero, ahora se relaciona uno con los objetos, así disponen Adorno y Horkheimer en su auto de procesamiento contra la razón instrumental, «como el dictador con los hombres», esto es, «en la medida en que puede manipularlos» ${ }^{56}$. Sin embargo, la mecánica visual y su correspondiente implicación ontológica cambian por completo en cuanto se considera que «un proceso no es posible sino gracias a la vinculación íntima entre dos fuerzas» y que en tales circunstancias tanto «sujeto como objeto son factores dinámicos que surgen, se amplifican, totalizan y desaparecen ${ }^{57}$. No hay entonces ni preexistencia ni duración, ni diferencia categórica ni conflicto alguno; por no haber, no existe siquiera la necesidad de afrontar una consolidación de la experiencia, habida cuenta de que el individuo ha renunciado a toda autoridad. A poco que uno conciba semejante régimen guiado por la empatía y por relaciones de pura necesidad, «toda distinción entre un sujeto y un objeto significará en último término una actitud retrospectiva y un sálvese quien pueda de la acción, una desintegración del acontecimiento ${ }^{58}$. Literalmente revolucionario, dialéctico en su más estricto sentido, este campo de fuerzas será precisamente la solución que proponga y abandere el cubismo frente a la separación de poderes donde enraíza la esclerosis moderna:

«Esto marca la diferencia. Los objetos significan en adelante fases de nuestra actividad [...] Es decir, toda la fuerza del acontecimiento es ensamblada en el hombre activo, y es en esta reevaluación donde reside en parte el significado del cubismo, que

\footnotetext{
52 Ibíd., p. 337.

53 Ibíd., p. 293.

54 Ibíd., p. 324.

55 Ibíd., p. 317.

56 Th.W. Adorno; M. Horkheimer: Dialéctica de la Ilustración, Madrid, Trotta, 1994, pp. 64-5.

57 C. Einstein: Georges Braque, op. cit., p. 293.

58 Ibíd., p. 372.
} 
sobrepasa largamente la estrechez del hecho pictórico. Enfrentado a una tal mentalidad dinámica, tanto el yo estable como el objeto fijo no representan más que puntos extremos de la experiencia visual o del comportamiento fáciles de determinar. Ante un motivo ya no se adopta una actitud de observador, distinguiendo meticulosamente un mundo interior y un mundo exterior, sino que las cosas existen en función del hombre al mismo tiempo que él existe en función del mundo».59

La vieja identidad diferenciada se convierte ahora en pura y simple provisionalidad, a tal extremo que Einstein no dudará en emplear el término metamorfosis para aludir tanto a la incesante mutabilidad del proceso como a la insoslayable «fusión de dinamismos del sujeto y del objeto» ${ }^{60}$. Si ya en Die Fabrikation der Fiktionen puede leerse que, así como «el primitivo cree en la metamorfosis puesto que su yo no está acotado, el moderno trabaja metamórficamente a consecuencia de una hipertrofia del yo» ${ }^{61}$, circunstancia que le impele a ser uno con el entorno para salvarse de sí mismo y de su fracaso como entidad autónoma, en Georges Braque esa alianza tácitamente indisoluble adquiere tintes dogmáticos y una importancia capital. Inútil añadir que, por cardinal que sea su función dentro del aparato ontológico einsteiniano, desde una lógica corriente el planteamiento de una entidad conjunta sujeto-objeto es poco menos que inconcebible, y que apenas puede representársela uno de forma topológica a la manera de Lucien Massaert, cuando se sirve de «una cinta de Moebius, por ejemplo, donde localmente sujeto y objeto se distingan como las dos caras de la cinta y al mismo tiempo y globalmente, como cinta de una sola cara, sean continuidad» ${ }^{62}-\mathrm{y}$ continuidad en constante movimiento, imposible de fijar.

Dar a ver este acontecer conjunto pone en serios aprietos al pintor, por descontado. En términos puramente psicomotrices, habida cuenta de que «el espacio no tiene sentido más que en tanto que proyección de la energía humana ${ }^{63}$, y visto que ésta presenta una variabilidad constante, se sigue en buena lógica que la configuración del espacio o del volumen inserto en él varíe sin cesar, lo cual exige del pintor una extraordinaria capacidad para fijar siquiera una reducida secuencia de cambios metamórficos y rendirlos gráficamente. Si para el pleinairista constituía una ímproba tarea plasmar el mínimo común denominador de la escena, esto es, la media de las modificaciones causadas por las variaciones atmosféricas en el curso de su contemplación, en el cubismo el asunto se complica sobremanera porque ya no se trata de establecer una imagen especular del objeto sino el riguroso memorándum de su génesis en un observador que no deja de danzar a su alrededor, dándole forma, modificándolo y relativizándolo sin descanso. Puesto que «toda percepción no es más que fragmento psíquico» ${ }^{64}$ altamente inestable, en el hecho pictórico adquiere una extraordinaria importancia «la dimensión memoria, es decir, la integración [...] de las vistas que uno no

59 Ibíd., p. 339.

60 Ibíd., p. 294.

61 C. Einstein: Die Fabrikation der Fiktionen, op. cit., p. 238.

62 L. Massaert: «Einstein/ 'Braque': de la projection imaginaire à la structure subjective», en M. Kroger; H. Roland (eds.): Carl Einstein im Exil. Kunst und Politik in den 1930er Jahren, Múnich, Wilhelm Fink, 2007, p. 254.

63 C. Einstein: Georges Braque, op. cit., p. 321.

64 Ibíd., p. 326. 
abarca al mismo tiempo» ${ }^{65}$, gracias a la cual «el motivo ya no es una cosa objetiva separada del espectador [sino que] la cosa vista participa de la actividad de este último, que la clasifica según la sucesión de sus percepciones ópticas subjetivas» ${ }^{66}$. En efecto, si «concebimos los objetos como relaciones cambiantes de funciones variables [que] se construyen espontáneamente en el seno de la experiencia inmediata ${ }^{67}$, se impone dar cuenta de ello mediante una articulación gráfica suficientemente elocuente, ni ceñida a lo convencional ni a lo plenamente arbitrario. Denomina Deleuze catástrofe al desorden que en tales circunstancias acontece en la mente del pintor y diagrama al «caos-germen» o «zona de limpieza» — suyas son también las expresiones- donde se traduce en signos plásticos ese desorden ${ }^{68}$, y el caso es que el cubismo descubrirá que la solución a todo ello existe ya, sepultada bajo un cúmulo de clichés vinculados al nivel de acabado o al imperativo naturalista, en el procedimiento mismo que guía la confección de todo cuadro que se precie. Braque o Picasso encuentran un diagrama o principio de significación suficiente en aquello que suele constituir el estadio inicial de la obra, en una esquemática yuxtaposición de planos que interactúan a despecho de cualquier modulación porque timbre cromático y claroscuro se comportan en esa fase como factores estrictamente locales, no coyunturales, y porque a esas alturas no hay asomo de gradación escalar o escorzo alguno. La habitual etapa provisional de la obra se convierte así en definitiva, pues, como indica Einstein, «las formaciones de antaño son en adelante anotadas en una visión homogénea, plana y, pese a todo el enriquecimiento espacial, es lo gráfico primitivo lo que es acentuado y lo que sirve de dispositivo para sustraerse a la convención óptica» ${ }^{69}$. Además de certificar una revolución en la constitución de la obra, en términos connotativos poner a la vista el armazón estructural comporta extraer el máximo de lo mínimo, sustraerla a toda estilización distorsionante y mantenerla activa a perpetuidad, por cuanto forma y contenido se amalgaman merced a la precariedad de lo inconcluso y eternamente naciente. Descuajaringados, víctimas de una destrucción que constituye su salvación misma y su regreso a la vida, presos de una tramoya entre geométrica y orgánica, entre hiriente y acogedora, los objetos cohabitan y así constituyen una nueva realidad; «cada parte de la figura está ligada a un campo formal preciso que se une a otras por analogía [...] formas y elementos de motivos son así prolongados dentro de los estratos de otros objetos [...] por medio de una transparencia de los campos formales» ${ }^{70}$. Atendiendo a su ontogénesis pudiera parecer que todo cuadro así configurado es mero capricho, pura labilidad, pero esa impresión se esfuma tan pronto como comprobamos su poderosa capacidad para alterar el estado normal de las cosas y hacer de la anormalidad un hábito duradero, es decir, para evidenciar, como Einstein apunta en otro momento y lugar en referencia a la obra de Klee, que «todo ser y toda forma aparentemente segura es una casualidad, y que el sentido del

65 C. Einstein: «Abhandlung von Sehen», en Werke. Berliner Ausgabe, Band IV. Aus dem Nachlaß I (Hermann Haarmann, Klaus Siebenhaar eds.), Berlín, Fannei \& Walz, 1992, p. 252.

66 C. Einstein: «Notes sur le cubisme» (1929), en AA.VV.: Documents Vol. I, op. cit., p. 153.

67 C. Einstein: Georges Braque, op. cit., 333.

68 Cfr. G. Deleuze: Pintura. El concepto de diagrama, Buenos Aires, Cactus, 2007.

69 C. Einstein: Georges Braque, op. cit., p. 363.

70 Ibíd. 
ser humano no descansa en la permanencia sino en la transformación metamórfica y en la destrucción de las formas». ${ }^{71}$

Cabe insistir en el valor de esta configuración, clave a la hora de entender el procedimiento cubista y, por ende, la tesis que propone como alternativa a la prepotencia instrumental o a la holganza estética, porque si en el encuentro visual sujeto y objeto no son magnitudes herméticas sino, muy al contrario, vectores mutables e hitos provisionales de las energías en juego, otro tanto cabrá esperar que suceda al dar a ver su resultado a un espectador cuya mirada no puede ser más antagónica a la desinteresada percepción kantiana. De que el cuadro sea explícito reflejo de su génesis y esté «colmado y animado por la energía, al punto de adquirir la fuerza de un ser actuando de forma viviente ${ }^{72}$, se sigue en buena lógica que un espectador abierto a la contingencia salga a su encuentro y participe en un baile simbiótico - acto erótico lo denominará Einstein en más de una ocasión- donde los viejos apriorismos y los roles enquistados, al igual que sucediera en el propio hecho pictórico, son puestos en cuestión y abolidos sin más.

Tanto es así, a tal punto es expeditiva esta nueva modalidad metamórfica, que bien puede apreciarse en ella un cuádruple carácter mortal. Mortal, en primer lugar, porque «el cuadro significa el final de un cierto proceso, lo cual hace de toda figura fija la fase terminal de un proceso de muerte» ${ }^{73}$, una violencia atajada a tiempo. Mortal por la propia configuración del acto receptivo, pues «de resultas de un agotamiento debido al extremo esfuerzo y a la concentración de energía psíquica en un segmento estrecho, se produce una anestesia con respecto al mundo circundante», un dramático ensimismamiento, de modo que, «cuanto más fuerte sea la concentración psíquica, tanto más son rechazadas y eliminadas las relaciones entre los recuerdos, las demás experiencias y las representaciones ${ }^{74}$, es decir, con tanta más rotundidad es anulado cuanto precede y rodea a la escena. Mortal, también, por la puesta entre paréntesis del espectador medio, sometido a un derrumbe de su atávica pasividad que arrastra consigo, como no podía ser de otro modo, al sempiterno yo homogéneo, pues «el efecto de la obra de arte reside ante todo en la anulación del contemplador» ${ }^{75}$, y siendo él mismo quien se ha expuesto a ello, Einstein no tendrá reparo en hablar de una «especie de suicidio» ${ }^{76}$. Mortal resulta, en fin, la acción que sin solución de continuidad lleva éste a cabo al apartar el cuadro de su vista o permitir que se desvanezca ante sus ojos. Es en esta fase donde queda perfectamente claro que «la totalidad misma del cuadro es un estado provisional que se desintegra fuera de la experiencia visual del cuadro» ${ }^{77}$, que «la cosa cuadro no es sino una apariencia $\gg^{78}$, fungible como un ser o un objeto cualquiera, y que su vitalidad se sostiene ante todo en la permanente amenaza de la muerte, en una insoslayable finitud que convierte en estéril toda diligencia estética en pro de su eternidad — no en vano, en la enseñanza que

71 C. Einstein: Werke, Band V. Die Kunst des 20. Jahrhunderts, op. cit., p. 267.

72 C. Einstein: Georges Braque, op. cit., p. 298.

73 Ibíd., p. 299.

74 Ibíd., p. 290.

75 Ibíd., p. 305.

76 Ibíd., p. 294.

77 Ibíd., p. 304.

78 Ibíd. 
esto proporciona a un ser humano obcecado por la inmortalidad situará Einstein «el valor biológico de todo arte» ${ }^{79}$, otra de sus formulaciones genuinas.

En esta tesitura, el cuadro, que «pasa por ser una fuerza viva y un instrumento» ${ }^{80}$, no está dispuesto esta vez a ser pasto de los manejos reificantes de la estética o del mercado. Se acabó la era de las ficciones, de la retórica, de las idealizaciones: «los cuadros no brillan ya como relucientes máquinas de juego sino como hechizantes instrumentos de poder para destruir y transformar el hombre y lo real [...] ahora los cuadros actúan en un sentido más profundo contra su tiempo y sus valores asociados» ${ }^{81}$. Largamente esperados bajo esta forma, hijos de una necesidad vital e histórica, su razón de ser se funda en buena medida en la aniquilación de aquello que los ha creado, puesto que si «el mundo ya no es considerado como una solución divina y definitiva, sino que al ser humano incumbe la tarea de inventar hoy de nuevo el mundo y el hombre - defectuosas soluciones provisionales—» ${ }^{82}$, el arte debe actuar en toda esta ceremonia insuflando caos para, acto seguido y mediante formas indóciles, perfilar lo por venir. El arte ya no representa ni al taimado poder intelectual ni al poder sancionado sino a una ambición multitudinaria, y por eso mismo «constituye de nuevo un riesgo» ${ }^{83}$, porque al recuperar su primitiva calidad funcional y comprometer como antaño hiciera a la sociedad donde se inserta, «las nuevas figuras son incorporadas a la realidad como prototipos» ${ }^{84}$ que «deambulan entre las cosas diurnas, actuando sobre ellas y relacionándose con ellas» ${ }^{85}$, y obligando al ser humano a hacer suya esa libertad que, ínfimas y provisionales como son, vienen a presentar. Pese a una aparente frialdad, el cubismo cuajaría así una mirada fuertemente empática hacia el mundo, una ética de la visión a la que acogerse en plena apoteosis de la razón instrumental, sancionando con ello «el carácter funcional de los cuadros, de lejos el más importante» ${ }^{86}$. Si el cuadro actúa, en definitiva, como fábrica de realidad, es porque la dota de un sentido que de otro modo pasa inadvertido o resulta impensable, pero ante todo porque ese más allá semántico orquestado en su seno enfrenta al espectador con su propia experiencia y le obliga a ponerla entre paréntesis y a replanteársela en el curso de la praxis cotidiana.

\section{Conclusiones}

Es de recibo recordar que Einstein preveía dar cauce escrito a sus reflexiones sobre pintura bajo la divisa La morale de la pureté; asediado por sus propios demonios y por un universo intelectual donde el componente ético brillaba por su total ausencia, y abrazando el espíritu ilustrado — que en aquel entonces ya lo era literalmente: puro fantasma—, Einstein quería creer que «en cada cuadro se contiene una situación moral» ${ }^{87}$ y que la pureza era su rúbrica distintiva. Pureza que no cabe entender en las acepciones tradicionalmente vincula-

79 Ibíd., p. 298.

80 Ibíd., p. 255.

81 Ibíd., p. 275.

82 Ibíd., p. 313.

83 Ibíd., p. 383.

84 Ibíd., p. 382.

85 Ibíd., p. 375.

86 Ibíd., p. 298.

87 Ibíd., p. 387. 
das al arte, dígase simplicidad técnica, elegancia formal o proyección espiritual, sino como limpia conexión entre la disposición creadora y su incidencia, entre intención y repercusión, entre hecho artístico y hecho receptivo. Que el rescate de un vínculo tan obvio se erigiera en reivindicación fundamental da la medida del contexto al que se enfrentaba, este es, un ámbito constituido por fórmulas de conveniencia, mecanicismos y expresiones de bajo vuelo urdidas al amparo de ideologías que tomaban el arte como campo de pruebas donde ensayar maniobras de largo alcance, con especial énfasis en la más letal de todas: el cortocircuito entre el individuo y su propia existencia, la desconexión entre el ser humano y lo real.

De hecho, cuando se declara enemigo del dualismo kantiano y sostiene que el espectador ha de ser «considerado como colaborador en la definición de cuadro» ${ }^{88}$, porque éste no existe sino en acto, Einstein está formulando una tesis de alcance netamente revolucionario. En una época que ve cómo saltan los goznes del arte canónico al cotejarlo con formas espurias - así Aby Warburg — y las de la convención contemplativa al poner en evidencia su fatídico carácter cultual —Benjamin—, Einstein da un paso más y emplaza la cuestión en una nueva tesitura, aquélla que desmantela de una vez por todas la hegeliana unicidad de la obra y la abre al concurso necesario del espectador, estableciendo su plena interrelación. En virtud de este cambio de perspectiva, a la anulación de cualquier variable que suponga una sumisión de la obra al estándar visual — mímesis, representación — se añade la de toda variable basada en la sumisión de la obra al individuo -impresión, efecto- y el convencional hiato entre uno y otro queda anulado en beneficio de una articulación horizontal, toda vez que «los cuadros son organismos dialécticos» ${ }^{89}$ a imagen y semejanza del ser humano y de la mismísima realidad.

Tal vez haya en esta antiestética, al igual que en el resto de la obra einsteiniana, un sustrato libertario difícil de asimilar, un poso demasiado radical que explicaría el ostracismo al que pronto fue relegada por una sociedad evolucionada y la aséptica curiosidad que, como viene sucediendo con todo lo apartado en los márgenes, ha podido suscitar mucho después. A fin de cuentas, pensarán muchos, quizá la suya sea una vía de acceso hacia una dimensión del arte digna de aprecio pero, al calor de los tiempos que no corren, comprometedora y audaz en exceso.

88 C. Einstein: «Abhandlung von Sehen», op. cit., p. 256.

89 C. Einstein: Georges Braque, op. cit., p. 303. 
